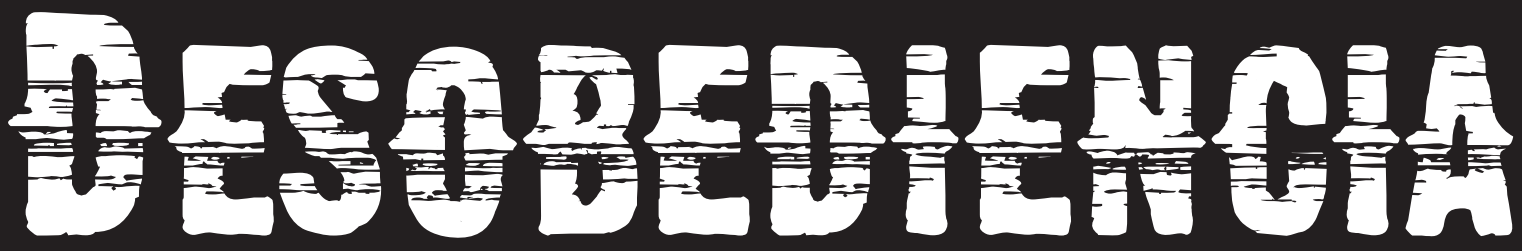

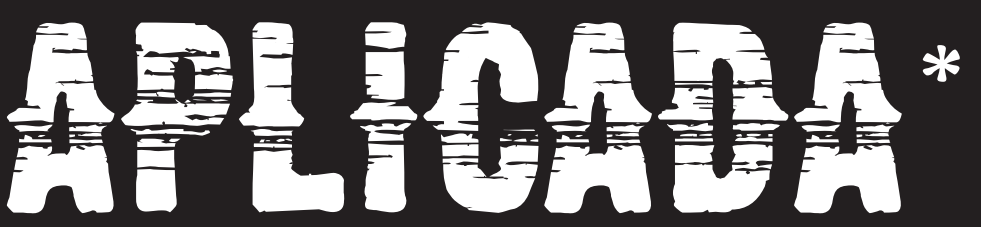

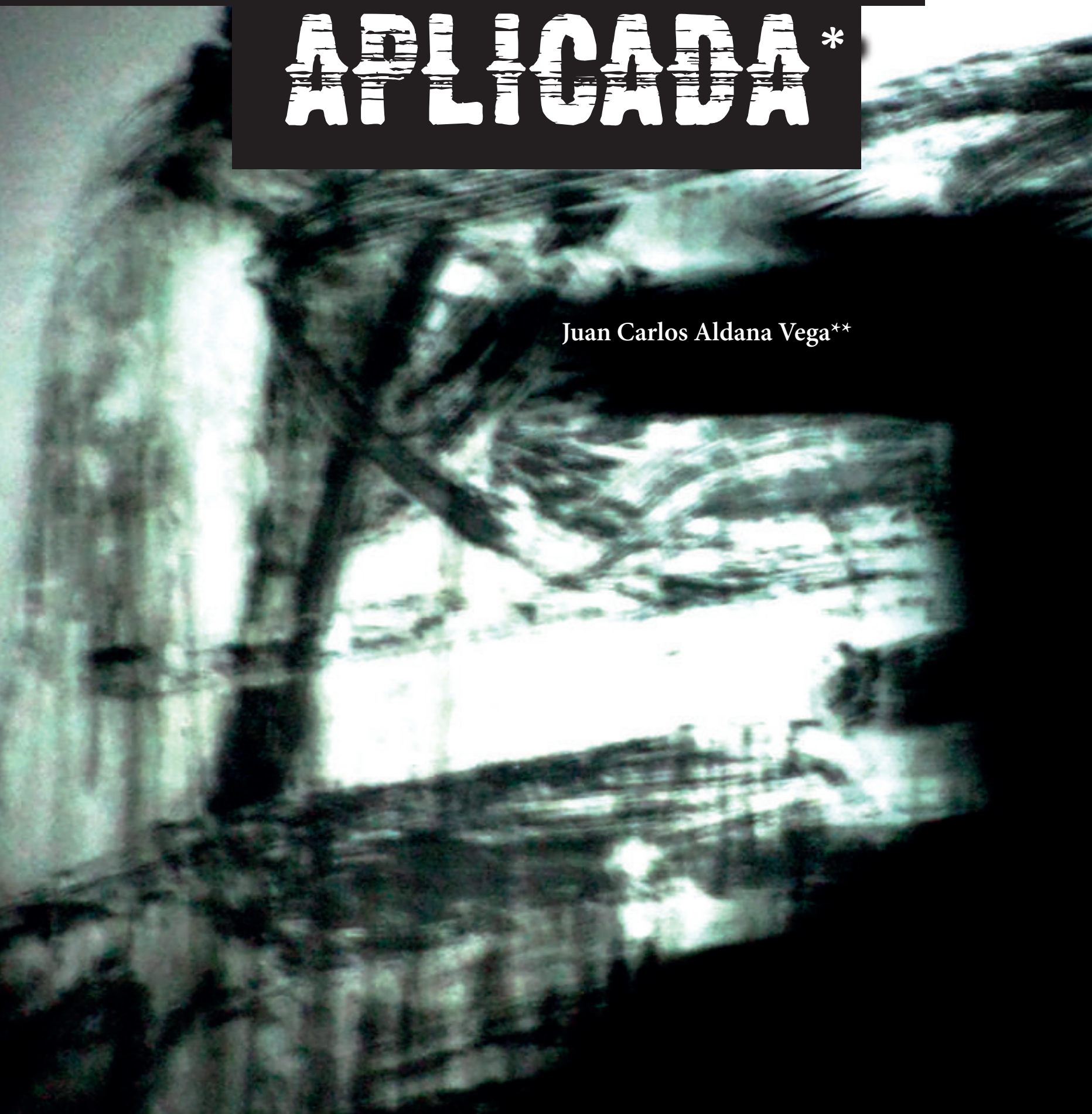

(c) $(1) \Theta$ 

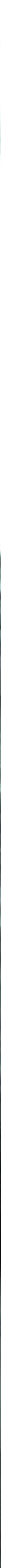
de Colombia, docente y jurado invitado por la maestría. juanaldana333@hotmail.com 


\title{
Resumen
}

Este ensayo busca trazar las posibles rutas metodológicas de un artista que decide crear en un espacio liminar disciplinar. Dicho espacio ocasiona necesariamente un descentramiento propio en las maneras de hacer, crear y pensar. Las relaciones tanto de correspondencia y de alteridad entre las disciplinas producen otras maneras y modos de abordar la creación en el campo artístico y del conocimiento. Este texto pretende hablar desde la experiencia propia como artista, como una estrategia para articular relaciones de pensamiento en la creación artística, como una forma de constatar procesos de creación en espacios de turbulencia y contaminación disciplinar. Hablar de la experiencia propia de creación se hace necesario para vincular los procesos de creación con procesos de pensamiento que puedan generar nuevas epistemes en el campo de las artes. Reflexionar la experiencia de la creación es una forma de articular pensamiento. El descentramiento propio de la disciplina o de los modos de hacer implica un proceso in disciplinar. Dicho proceso parte de operaciones sinérgicas entre lenguajes y disciplinas de las artes que son posibles en las Artes Vivas. Esta reflexión surge a partir de la experiencia como estudiante y como docente invitado de la Maestría Interdisciplinar de Teatro y Artes Vivas de la Universidad Nacional de Colombia. Abre la necesidad de recoger la experiencia de creación y de investigación en el tiempo, del resultado final de obra y texto de grado de maestría.

Palabras clave: Artes Vivas; disciplina; indisciplina; creación; pensamiento; experiencia.

\section{Applied Disobedience}

\begin{abstract}
This essay seeks to trace the possible methodological routes of an artist who decides to create in a disciplinary liminal space. This space necessarily causes its own decentration in the ways of doing, creating and thinking. The relations of correspondence and otherness between disciplines produce other ways and means of approaching creation in the artistic and knowledge field. This text intends to speak from one's own experience, as a strategy to articulate thought relationships in artistic creation, as a way of verifying creation processes in spaces of turbulence and disciplinary contamination. Talking about one's own experience of creation is necessary to link the creation processes with thought processes that can generate new epistemes in the field of the arts. Reflecting on the experience of creation is a way of articulating thought. The de-centering of the discipline or of the ways of doing implies an in-disciplinary process. This process is based on synergistic operations between languages and disciplines of the arts that are possible in the Living Arts. This reflection arises from the experience as a student and as a visiting professor of the Interdisciplinary Master of Theater and Living Arts of the National University of Colombia. It opens up the need to collect the experience of creation and research over time, from the final result of master's degree work and text.
\end{abstract}

Keywords: Living Arts; discipline; indiscipline; creation; thought; experience

\section{Desobediência aplicada}

\section{Resumo}

Este ensaio não pretende apresentar uma tese sobre o que é disciplinar nas artes, mas procura traçar os possíveis percursos metodológicos de um artista que decide criar num espaço liminar disciplinar. Esse espaço necessariamente provoca sua própria descentralização nas formas de fazer, criar e pensar. As relações de correspondência e alteridade entre disciplinas produzem outras formas e meios de abordar a criação no campo artístico e do conhecimento. Este texto pretende falar a partir da própria experiência, como estratégia para articular relações de pensamento na criação artística, como forma de verificar processos de criação em espaços de turbulência e contaminação disciplinar. Falar sobre a própria experiência de criação é necessário para vincular os processos de criação aos processos de pensamento que podem gerar novas epistemes no campo das artes. Refletir sobre a experiência da criação é uma forma de articular o pensamento. $\mathrm{O}$ descentramento da disciplina ou dos modos de fazer implica um processo indisciplinar. Este processo é baseado em operações sinérgicas entre linguagens e disciplinas artísticas que são possíveis no Living Arts. Esta reflexão surge da experiência como aluno e como professor visitante do Mestrado Interdisciplinar de Teatro e Artes Vivas da Universidade Nacional da Colômbia. Surge a necessidade de recolher a experiência de criação e investigação ao longo do tempo, a partir do resultado final do trabalho e do texto do mestrado.

Palavras-chave: artes vivas; disciplina; indisciplina; criação; pensamento; experiência. 
Las Artes Vivas provocan el advenimiento de un espacio para la experimentación entre disciplinas, lenguajes y medios. Actúa como un lugar propicio para la expansión de las disciplinas en sus operaciones múltiples. El interés de este texto es hacer una reflexión alrededor de las operaciones indisciplinares en las artes. El espacio de convergencia y diálogo entre los diferentes lenguajes artísticos, que podríamos denominar como práctica interdisciplinar, no pone en riesgo las propias disciplinas, no es un espacio de crisis. Quisiera, por tanto, hablar mejor de las prácticas indisciplinares como operaciones posibles que expanden y ponen en crisis el campo del conocimiento y la creación en las artes. Lo indisciplinar solo puede ocurrir como un acto de desobediencia y de negación de lo canónico, de lo disciplinar: una rebeldía implícita en su devenir no siendo.

No siendo es como perder el rostro

Mi presencia no representa a nadie, no soy yo, no soy Hamlet y menos el espectro. Mi naturaleza no es la de un personaje, simplemente soy el operario de un dispositivo escénico. Lo acciono y soy el impulso, la fuerza que se conecta a otras fuerzas. Soy la palanca que gira la rueda, soy el accidente y soy la fuga. (Aldana, 2009, p. 27)

La desobediencia disciplinar es una trans-acción que implica deslizamientos, desplazamientos, es perder lo propio en pos de una apertura a lo frágil, a lo precario, a lo desconocido; es un espacio de turbulencia y caos que actúa en los intersticios de las disciplinas, en sus bordes y fronteras; es un campo en disputa y tensión entre disciplinas cuyo fin es ir más allá de lo disciplinar o romper con la disciplina propia; es una zona de problematizaciones e interrogaciones que potencian lo ambiguo, la incertidumbre y la sospecha; es un producto mutante de intercambios, de interacciones, de colisiones y, por consecuencia, de alteraciones y modificaciones; es nómade porque va de un lugar a otro sin establecer residencias fijas, en lugares de tránsito sin formas de identidad; es deconstrucción, movilización y subversión del orden de lo establecido: identidad, verdad, sujeto o ideología; es un acto de ruptura, disrupción y transgresión.

Considero que todas estas frases apuntan a un manifiesto político sobre la desobediencia disciplinar, tienen sentido y verdad si se hablan desde la experiencia y la práctica misma. Mi interés, más allá de una verificación académica de las prácticas artísticas indisciplinares, es hablar del artista que decide operar en un campo de turbulencia, desajuste y caos disciplinar como propuesta para sus creaciones. La puesta en acción de este espacio donde el artista se propone a sí mismo como un laboratorio es su apuesta política, es su posibilidad de poner en crisis sus modos de hacer y de acontecer en un mundo expandido y globalizado, donde fracasan día a día las formas de representar y representarse. El artista pierde necesariamente su rostro: no siendo se expande hacia otros lenguajes y se reconstruye de nuevo. No siendo es la condición de partida, partir de nada.

La imagen de turbulencia y caos no remite a espacios de convergencia y diálogo entre disciplinas. Remite más bien a una antropofagia disciplinar, un banquete desaforado donde las disciplinas se devoran unas a otras por medio de la creación de hibridaciones, mestizajes, transvestimientos, diseminaciones, desapariciones, extravíos, desvaríos... Un banquete entre disciplinas, una orgía entre la belleza y el horror, un espacio para la virulencia altamente contaminante donde se pierde toda unidad y toda diferencia. Posiblemente asistimos a una belleza decapitada o una sublimación del horror en la caída de los monumentos. Este momento de turbulencia orgiástica es el posible arribo a la nada, o posiblemente el estado que conecta con un proto estado donde somos todo y a la vez nada. Un espacio de ambigüedad, de tensión constante cuyas fuerzas siempre apuntan a la crisis y al caos. Crisis necesaria para resistir la forma y toda conciencia de contenidos. Caos necesario para sostener la desobediencia como un lugar del desajuste de todo orden. 
La indisciplina, por tanto, propone el caos, la crisis y la desobediencia como una ruta posiblemente "metodológica" para plantear procesos de creación otros. La desobediencia es cosa de maleducados, de indisciplinados. Posiblemente el indisciplinado nunca ha podido tener disciplina. Es y no es, siempre se constituye un no siendo soy. El indisciplinado no es un competente y tampoco tiene habilidades y capacidades, realmente se mueve en el campo de la ignorancia y la incompetencia. Sus diferentes translaciones, deslizamientos y apropiaciones en las diferentes disciplinas donde se moviliza le posibilitan pensarse y nutrirse desde otros lugares. En sus migraciones disciplinares hace uso del conocimiento de otros, reflexiona la filosofía a su acomodo, hace sus propias conjeturas y relaciones de pensamiento alrededor de sus creaciones. Sus incursiones y apropiaciones en otros saberes no dejan de instalarse en espacios frágiles y precarios del conocimiento y del hacer, pero potencian otras formas de creación y pensamiento, y, sobre todo, de resistencia.

\section{La fuga y la desaparición de las presencias mismas}

Mi interés, como planteé más arriba, es hablar acerca de las operaciones indisciplinares en las Artes Vivas por parte de artistas que deciden crear desde estos lugares de turbulencia y de caos. No podría generalizar que todos los procesos de creación indisciplinares sean iguales; todo lo contrario, todos son necesariamente diferentes porque sus rutas de acción pueden ser múltiples e infinitas. Tampoco podría dar cuenta de unas metodologías precisas porque la práctica misma tiene la condición de laboratorio: la creación-pensamiento en un campo en experimentación continua. Hablar posiblemente desde el lugar de la experiencia de una puesta en juego de creación indisciplinar, sería la condición para poder salir de una exclusiva reflexión académica teórica acerca de la desobediencia y su condición emancipadora. Me voy a referir, por tanto, a experiencias propias de creación que pueden dar un atisbo de estas operaciones de trans-acción indisciplinar. Los siguientes fragmentos se desprenden de reflexiones acerca de la naturaleza del proceso de creación pensamiento del trabajo No es lo mismo Dinamarca que Cundinamarca: Hamlet o el diálogo espectral.

No es lo mismo Dinamarca que Cundinamarca: Hamlet o el diálogo espectral no solamente es un compromiso político como artista frente a la guerra que cursa Colombia, sino frente al arte y las políticas que asumamos frente al dolor y a las víctimas. No se trata de un proceso exclusivamente estetizante del conflicto, sino de asumir un tipo de ética frente al hecho mismo de su representación. (Aldana, 2009, p. 35)

Las fosas, los huesos, los ropajes, los objetos y los escapularios son el equipaje de viaje del espectro, y ahora se suman a mi inventario de creación. Los gritos y las motos sierras son el eco mudo atrapado en dichos territorios de muerte. Los gritos y las sierras son las voces espectrales que empezaron a atrapar mi universo espectral sonoro. En la alegoría encuentro en la presencia lo que se potencia en la ausencia. Y en el emblema, las imágenes de horror que son el compendio de nuestra historia, una historia de barbarie. (Aldana, 2009, pp. 23-24)

La exposición de cadáveres en lugares públicos es un signo y una imagen que se fijan, cuyo fin es aterrorizar. El terror opera tras la imagen 
del cadáver, esparce la muerte con violencia, y silencia toda voz a su paso. Él se expone directa y crudamente en el cadáver en presencia pura, sin mediaciones ni adornos. Es la imagen que trastorna y horroriza: es la alegoría en potencia. (Aldana, 2009, p. 22)

La escena no solamente abría la historia de un acontecimiento, sino que albergaba mi condición de vida. Era yo frente a Yo Hamlet, era yo frente a millares de espectros, era yo pintor y era yo simplemente. (Aldana, 2009, p.27)

Estos fragmentos revelan un contenido de reflexiones teóricas obtenidas de lecturas disgregadas que vienen de la literatura, del drama teatral, del teatro, de la filosofía, de los medios periodísticos, de la red, de la televisión, de auto referencias y cualquier otra cosa que pudiera articular y vincular procesos de pensamiento con procesos de creación. Las lecturas fragmentarias no alcanzan a constituir un cuerpo teórico sólido para sostenerse; en su lugar, es precario y frágil. Pero precisamente esta condición era la potencia para la creación. Los fragmentos se convertían en un collage de pensamientos que se transferían en imágenes corporales, pictóricas, visuales y sonoras. Esta operación de transducción entre pensamiento, escritura e imagen es una fuga y desaparición de las presencias mismas, pensamientos que se desvanecen en imágenes, imágenes que alcanzan pensamientos. Solo un devenir no siendo, solo derivas y acercamientos efímeros entre fronteras opacas y difusas del conocimiento y el pensamiento.

\section{Diseminaciones, extravíos y remedos}

El fragmento dice "era yo pintor y era yo simplemente" pone de manifiesto la relación autorreferencial dentro el repertorio intertextual que la obra propone desde de su proceso de creación. Fragmentos del Hamlet de Shakespeare y Müller, fragmentos de los medios y fragmentos personales de vida: un yo y un pintor. Aquí necesariamente debo poner en evidencia ciertos antecedentes artísticos que pueden iluminar más esta disertación. Mi formación parte ya de una estructura indisciplinar o multidisciplinar: pintor autodidacta, intentos de actor de cine, bailarín clásico con una efímera experiencia de cuatro años, licenciado en escenografía en Arte Dramático y magíster interdisciplinar en Teatro y Artes Vivas, formación inicial que se estructura desde las Bellas Artes donde el artista se construye a partir del oficio y de una tradición, de un arte mimético y de imitación, disciplinar, delimitado, canónico y colonialista. 
somos instruidos en el arte de la imitación y el remedo.

Remedo de escuelas, repeticiones y memorizaciones del conocimiento como institución de la verdad, del logos. Remedo salvaje de la lora que, repite sin conciencia, solo es remedo. Sus graznidos construyen otro diagrama, otra "conciencia": un pensamiento del remedo, extraviado y diseminado; un pensamiento que opera en la desobediencia, y desde su alteridad misma.

El primer encuentro con el proyecto No es lo mismo Dinamarca que Cundinamarca:

Hamlet o el diálogo espectral fue en su agonía: tuve que destrozarlo y matarlo. Tenía una necesidad profunda de una muerte mutua, tanto la mía como la del proyecto. Presencié mi dilución y mi añorada muerte. Se abría un gran abismo que tenía que abismar: mi forma de representar el mundo como creador, colapsaba. Y el proyecto, en su postulado inicial, también se fisuraba, respondía a una muerte que nacía de la muerte, de la decepción misma y de la necesidad de una muerte propia. Había que matarlo por su imposibilidad misma de ser representado. (Aldana, 2009, p. 16)

Una agonía necesaria de muerte, una puesta en crisis necesaria. Si la Representación del mundo colapsaba, si la Civilización colapsaba en su síntoma de barbarie y catástrofe, toda forma de representación del arte colapsaba. Ese yo, ese pintor, colapsa ante la "ineficacia" de su repertorio sensible ante un mundo que también muere y se desconfigura, donde todo es masa, todo es igual. Su condición de artesano muere porque al parecer ya no dice nada. Sin embargo, toda muerte es necesaria porque invoca el nacimiento. Esparcir y diseminar la experiencia sensible como artista en pos de operaciones de riesgo y crisis, indicaba una ruta nueva para negarse a la desaparición completa. Aventurarse en la desaparición propia implica necesariamente llevar como equipaje de viaje la experiencia. Sin ella no se tiene nada para diseminar o desaparecer, ella es el diagrama secreto de la lora salvaje.
El texto de varios textos que mencioné anteriormente quedó recluido en un cajón. Su destino por ahora sería el olvido (más tarde sería retomado, pero con otro sentido). De él solamente me quedé con algunas palabras, como "muro, espectro, verdugo, víctima, sangre y escupitajo. Las palabras tienen eco, y resuenan en imágenes" (Aldana, 2009, p. 24).

Solo tenía una suerte de imágenes difusas en mi cabeza, y una colección de objetos. Además, tampoco quería un texto, y hoy considero que darle muerte al proyecto fue, no solamente un acto de valentía (o de cobardía), sino de sabiduría. Tal vez apelaba a mecanismos que pudieran afectar la representación. También quería apartarme del Teatro y de todas sus estrategias para la creación: tenía una alterada fobia teatral (Aldana, 2009, p. 25).

La crisis potenciaba un diagrama nuevo para establecer nuevas rutas para crear. El yo artista se diluye, el pintor se lanza al abismo de su propia muerte. Ahora es un mutante, un zombie, un depredador o la lora salvaje. La lora domesticada rompe con sus graznidos la repetición y el remedo. El artista opta por el graznido en su melancólica búsqueda de su exótico ancestro, por su salvaje, por su Calibán. Ahora sufre de extravío, se para en tierra de nadie. El mundo ha cambiado, los monumentos se desploman, asistimos a la caída del genio. Adiós genio, adiós artista.

Soy el espíritu que mutó en espectro: el artista que no construye en su imagen, sino en su espectralidad. Lo espectral tiene de especular, la imagen refractada en el reflejo es su fantasmagoría. La pintura permanece ahí en su espectralidad, en su ausencia presencia, en su fantasmagoría. Su muerte la elevó a la condición de espectro donde configura su nuevo diagrama; donde participa del banquete antropofágico al que fue invitada. Su nueva condición de zombi depredador la sumerge en la bacanal más placentera y lúdica que jamás haya tenido. Se sumerge en la espectralidad de otros lenguajes y confabula una táctica de diseminación y dispersión de todas sus espectralidades.

Mi cuerpo ante lo que no se nombra se silencia, no tiene yoz. El diálogo espectral 
entre yo y los millares de espectros surgía en la retirada, en la desaparición,

en la dilución de la voz, en el muro...soló el gesto de manchar, borrar, lavar

se constituía en el diálogo. De la acción surgían las voces, las palabras del

espectro que reclama. Yo soy la cuerda por donde desciende la muerte con sus

espectros reclamando su misma muerte. (Aldana, 2009, pp. 29-30)

rat

\section{Soy la palanca que gira la rueda, soy el accidente y soy la fuga}

La segunda etapa de formación del artista espectral se generó en el proceso de laboratorio de la Maestría Interdisciplinar de Teatro y Artes Vivas, espacio para la confabulación y la alteridad, para la muerte y la espectralidad. Este espacio posibilitó una zona altamente experimental de puestas en riesgo de lo disciplinar, de los lenguajes y de los medios, de los modos de hacer y operar de nuestras prácticas artísticas. Las escuelas clásicas de las Bellas Artes, en tanto a las figuras del pintor, del escenógrafo y del bailarín clásico entraban en una zona de expansión y contacto con otros lenguajes que podían potenciar, mutar, transformar sus maneras de pensar, hacer y crear.

El cuerpo respondía a las imágenes visuales y sonoras, encontraba su espacialidad y su temporalidad. El espacio: un muro. El tiempo: el cuerpo que es la fuerza que intenta derribar el muro. El muro: un video que el cuerpo intenta borrar. La imagen: la fantasmagoría, el universo espectral. Motivo: un crimen. Involucrados: un espectro, un verdugo y una víctima, y millares de espectros. Desaparecen: el espectro, Hamlet, Ofelia, Pastora y su hija. Y solamente queda el título: No es lo mismo Dinamarca que Cundinamarca: Hamlet o el diálogo espectral, y sus vestigios (Aldana, 2009, p. 33).

El soporte para los videos y la acción pictórica era el muro o la pared. El gesto con mi cuerpo de escribir y borrar, o de sobrescribir y tachar, o de lavar y lavar, en simultáneo con el pasar de imágenes en video, intentaba liberar las voces incrustadas o de hecho las voces espectrales. El muro que habla y el cuerpo que lo interpela. "Entre nosotros crece un muro mira lo que crece en el muro"1 (Aldana, 2009, p. 28).

La desaparición de un texto, con sus personajes, y todo su ajuar de acciones, y elevarlos a la condición de vestigio, se convertía en una posible táctica de creación fundada en la fantasmagoría. Transitar entre los límites de los lenguajes, intersticios propios para la desaparición, la diseminación y el desajuste. El cuerpo diseminado entre la pintura, el dibujo, la escritura, el video, lo sonoro, hablaban de una estructura otra de artista, del artista indisciplinado. Trabaja en tierra de nadie; toma prestado o se roba lo de los otros; su paso es espectral en la aparición y desaparición; es incompetente e ignorante en sus trans-acciones con otros lenguajes que no son parte de su naturaleza; sus trans-acciones son precarias porque desconoce las herramientas; su precariedad, su ignorancia y su incompetencia en el uso de otros medios y lenguajes "lo pueden elevar de patito feo a cisne, o ser un fracaso completo"; es una lora domesticada con ínfulas de salvaje; también intenta desaparecerse en su propia nada...

1 "Entre nosotros crece un muro" (Müller, 2008) Frase escrita sobre el soporte muro con la que se da inicio a la obra No es lo mismo Dinamarca que Cundinamarca: Hamlet o el diálogo espectral. Esta frase alude el muro que nos separa, el muro donde se inscribe nuestra violencia como memoria y testimonio de nuestra barbarie. 
La pintura no tenía para mí ninguna eficacia, realmente me aburría. Y la escenografía ocupaba el espacio olvidado de siempre, esa sombra que pasa tras bambalinas: no dejaba de ser un órgano viejo del Teatro que cada día está más en desuso. Sin embargo, la pintura y la escenografía eran mi equipaje de viaje de vida, y eran mi vida. Además, era lo único que tenía, y sabía hacer. (Aldana, 2009, p. 25)

Mi cuerpo entró en diálogo con los videos, mediante una intervención pictórica donde se accionaban textos, borrones, chorreones, y dibujos. La acción que realizaba mi cuerpo sobre la escena era la de pintar. Era yo en presencia, ejecutando lo que he hecho durante toda mi vida, pintar. (Aldana, 2009, p. 27)

Ese no poder ver, pero sí ser mirado. El que está ahí presente, se ve y no se ve. Ésta condición ambigua de lo espectral, era lo que posibilitaba su condición de ser representado. Aquello, que es más potente por su ausencia que por su presencia: su no representación abría la posibilidad de nombrar sin nombrar. (Aldana, 2009, p. 29)

\section{El crepúsculo disciplinar}

Después del sagrado banquete y sus desmesuras queda el cansancio. Ya no hay deseos de muerte ni dramas. ¿Para qué?, pregunta la lora despiadada al melancólico artista espectral. El artista ha emprendido un viaje sin retorno, es el extraño y extranjero adonde vaya. Todo lo que ha recogido por su camino, su corpus estético lo extiende para observarlo y ante todo para escucharlo. Es un placer entender cada lugar, cada salto, cada deslizamiento, cada transacción, cada operación desde la disciplina o no disciplina, ante todo disfrutar de las pequeñas particularidades que resuenan de otra manera desde el extravío. Es un momento para sentarse y observar nuestro paisaje en silencio. ¡Y sobre todo seguir perdiendo el tiempo! 


\section{Referencias}

Aldana, J. (2009). No es lo mismo Dinamarca que Cundinamarca. Hamlet o el Diálogo espectral. [Tesis de maestría, Universidad Nacional de Colombia].

Müller, H. (2008). La Máquina Hamlet. La Cifra Editorial.

\section{Abordajes conceptuales para la creación}

Canclini, N. (2010). La sociedad sin relato. Antropología y estética de la inminencia. Katz Editores.

Castellucci, R. (2007) Gaz\#3: Interview Romeo Castellucci (Contemporary Dance). GazMagazine: https://www. youtube.com/watch?v=4mf0MFLBAiQ

Didi-Huberman, G. (2013). Cuando Las imágenes toman posición. Editorial Antonio Machado.

Didi-Huberman, G. (2015). Fasmas Ensayos sobre la aparición 1. Shangrila Ediciones.

Didi-Huberman, G. (2020). Desear Desobedecer lo que nos levanta, 1. Abada Editores.

Diéguez, I (2010). Atravesando los marcos escénicos: contaminaciones y liminalidades. Repertório. http://dx.doi. org/10.9771/r.v0i14.4660

Dronsfield, J. L. (2010). Theory as art practice: outnotes for indiscipline. Art\&Research,
Ladagga, R. (2006). Estética de la emergencia: la formación de otra cultura de las artes. Adriana Hidalgo editora.

Mitchell, W. (1995). Interdisciplinarity and visual culture. Art Bulletin, 72(4), 540-544.

Nancy, J-L. (2006). La imagen Mímesis \& Méthexis. Escritura e imagen.

Mancilla, M (2007). Reseña de "Antropofagias. Las indisciplinas de la comunicación", de Victor Silva Echeto y Rodrigo Browne Sartori. Revista Austral de Ciencias Sociales, 13, 125-128.

Pavis, P. (2016). Diccionario de la performance y del teatro contemporáneo. Editorial Paso de Gato.

Rancière, J. (2002). El maestro ignorante. Cinco lecciones sobre la emancipación intelectual. Laertes, S.A. de Ediciones.

Van den Dries, L. (2006). Corpus Jan Fabre: Observations of a Creative Process. Editor Imschoot.

\section{Para citar este artículo}

Aldana, J. (2021). Desobediencia aplicada. (pensamiento), (palabra)... Y obra, (25). https://doi.org/10.17227/ppo. num25-13061 